\title{
Research on the Editing of Film Trailer in the Perspective of Large Data
}

\author{
Yan-Qiu TONG ${ }^{1, a}$, Qi-Hua REN ${ }^{2, b^{*}}$ \\ ${ }^{1}$ School of humanities Chongqing Jiaotong University Chongqing, China \\ ${ }^{2}$ Chongqing Telecommunication Polytechnic College Chongqing, China \\ ayqtong@126.com, b 493083263@qq.com \\ ${ }^{*}$ Corresponding author
}

Keywords: Large Data, New Media, Visualization.

\begin{abstract}
Movie trailers originate from the movies themselves. Although compared with the two-hour-long films, the trailers are insignificant. It takes certain skills to make moderate spoilers and sufficient gimmicks in this short period of time, while at the same time to hoist the audience appetite. Films are a result of cutting, so are trailers. But it' $\mathrm{s}$ obviously insufficient for us to analyze their relationship only from the angle of editing techniques and art. This study is based on the perspective of large data, in which the clips of the trailers are abstracted in visual scenes. Further more, when put back into the movies again, we can directly release the relationship between the trailers and the features.
\end{abstract}

\section{Introduction}

No matter how boring the film is, its trailer must be remarkable. The lenses of a movie are mainly from the film itself, but it doesn't you can find all the lenses in the feature. And this is exactly the charm of trailers. Most classical film trailers are fascinating. But for some films, the trailers look alluring, when walking in the theater, the features can be quite different from the trailers. Trailers are the essence of movies which attract the audience by impressing them with unforgettable images. From the time point of view, trailer has a history which is not shorter than films. The subtitle added at the end of Edison's film series What's Up in 1912 can be regarded as a sign of the birth of trailers. In 1916, Paramount Pictures Company set up a special department which is responsible for trailer issuing, after that this kind of department appeared at various movie companies.

Audiences decide whether to go to the theater by watching the trailers that are put into all kinds of media. And with the establishment of the American profession system, trailers got their own rules of game. Trailers can be divided into Teaser Trailer, Official Trailer and Super Trailer according to the current Hollywood system. Teaser Trailer, which feature short time, a few lenses, creators` information and the source of the story usually release 3 to 4 months or even 1 year before the entire movie come out. Official Trailers are most movies` standard configuration, and they often release 1 to 2 months ahead of the feature. In accordance with International convention, they are usually as long as 150 seconds. [1] They re-integrate the clips into a micro movie by specially editing arrangements. Super Trailers are longer than Official Trailers and consist of more wonderful content. In addition, some Super Trailers even include some clips beyond the feature.

If we regard movie as a kind of cultural product, then trailers will advertisement of this product. Thus, trailers also demand for marvelous insights, which mean extracting, and integrating the movie information and disseminating them to target audiences widely and effectively. Hollywood is seen as the headstream of commercial movies where trailers rank the first way of film selling. For a secondary-making film with a budget of $\$ 35$ million, it costs at least $\$ 2.5$ million to $\$ 7.5$ million to make a trailer. This kind of integrated system investment allows the trailer to guarantee its independence and quality. In the US, there are special awards to encourage trailer making. [2] 


\section{Theoretical background and research design}

Like the titbits, trailers have been derived from movies and become a kind of relatively independent film type. They have their own way unique standard of both producing and techniques. What's more, they possess independent disseminating system, process and original interests and aesthetics. [3]

A trailer is a window to see more about a movie as well as a means to for commercial marketing. Because trailers have the feature of both sound and images, it belongs to "experiencing marketing". As cultural product, the biggest difference between movies and material products is: movies are unlike foods or other articles of everyday use which requires the consumer to know as much as possible about them. However, for a commercial movie, if the audiences know all about the scenes, they will soon lose their curiosity and decide not to go the cinema. Thus, trailers must pass on the information of the movie limitedly and efficiently. So this requires the trailer maker to grasp the scale and make it alluring and mysterious.

An American writer V Road said in his book Chronicles of the suspense, "the dramatic story narrator hoist your appetite by alluring techniques... broadly speaking, he buried a boom which only explode in the end. In this way, he released the energy of the drama and this magic power is called suspense." At some point, a trailer is an advertisement with suspense which always stops at the highlight and freezes the plots to ice point from boiling point. The trailers make the atmosphere become tense, so as to stimulate the audiences` interests. [4]

At present, the theoretical basis about film trailer cutting is the "psychological pressure", which studies the massive structure from the angle of audience mentality. Mostly a mixture of truth and falsehood is used in film clips in which we omit the secondary plots and character in order to manifest the main idea, clues and some key details, leaving the room for audience to imagine and predict. This can cause some "psychological pressure" which pushes the audience to have the motivation of transforming the incomplete object. [5]

\section{Sample selection introduction}

In 2013, there were as many as 32 movies produced in China, the total box of office is 217.69 billion RMB. In all of the movies, the movie So Young ranked number 2 with 7.18 billion RMB and American dreams in China ranked number 5 with 5.3928 billion RMB.

The reasons why I chose those two movies to be my objects are: one the one hand, they are both well-selling movies labeled "youth", on the other hand, they are both released by ENLIGHT MEDIA. Those two movies indeed brought back the Chinese audiences' nostalgia and made it last from spring to summer. The female feelings reflected by So Young showed the mentality young girls have during love while American dreams in China is full of manliness and it tells the story of how three young men created their own business. Both So Young and American dreams in China are comparable. American dreams in China is more likely to bring back nostalgia, more inspirational and passes more positive energy. But So Young did slightly better than American dreams in China at box-office. [6] As two films with screening slots for only 21 days, the responsibility of contending for the audiences was laid on the trailers. Although both of them were labeled with "youth", what's the difference between them? Then here comes their value of studying.

\section{Research method}

ВсеволодИлларионовичПудовкин(1893-1953), one of the founders of montage theory, a famous director of former Soviet union, said, "the art of film is based on clips." Clip distinguished movies from other kind of art like music, dance, drawing, photographing and architecture. Thus clip is the sign for the movies to be as an independent art form. From the point of form, trailers are a result of clip, but from the point of art, it's a kind of manipulation of time and space. Different from trailer making, the study of trailer relates closely to the movies though it's also based on lenses. After all, most of the trailers' content is from the feature. 
In this study, I used the method of large data to study the trailers, which can be a brand trail. But there is one thing that I need to explain is: at present, the concept of large data for most people is just massive data which is too traditional and out of time. Traditional data study builds hypothesis first and then obtain the corresponding data, and finally verify the hypothesis by analyzing the data. However, large data is different from this. Large data analyzes the varied data collected from all kinds of channels by algorithm, and find out the relationship between those unstructured data. In short, large date pay more attention to the cycling process of discovery, guessing and verification while traditional study tend care about the sample design more. [7]

\section{The results of the study and analysis}

For those two movies So Young and American dreams in China selected in this study, the process of obtaining the lenses data is as followings:

At first, import the film to the video track by non-linear editorial software, (e.g. Adobe Premiere, Canopus Edius, Apple Final Cut ect.), and find the position of each lens in the feature. Then set the start point and ending point and put all the lenses on another track.

Secondly, the lenses clipped from the feature cannot be studied before digitalization. Thus the lenses need to be exported as EDL. EDL is the abbreviation for Editorial Determination List. EDL expresses the starting point and ending point of each lens by time code in which we can get some primary data. The EDL of trailer for American dreams in China is shown in figure 1.

Finally, extract all the lenses from the trailer and put them back into the feature by visualization method to form a visible diagram.

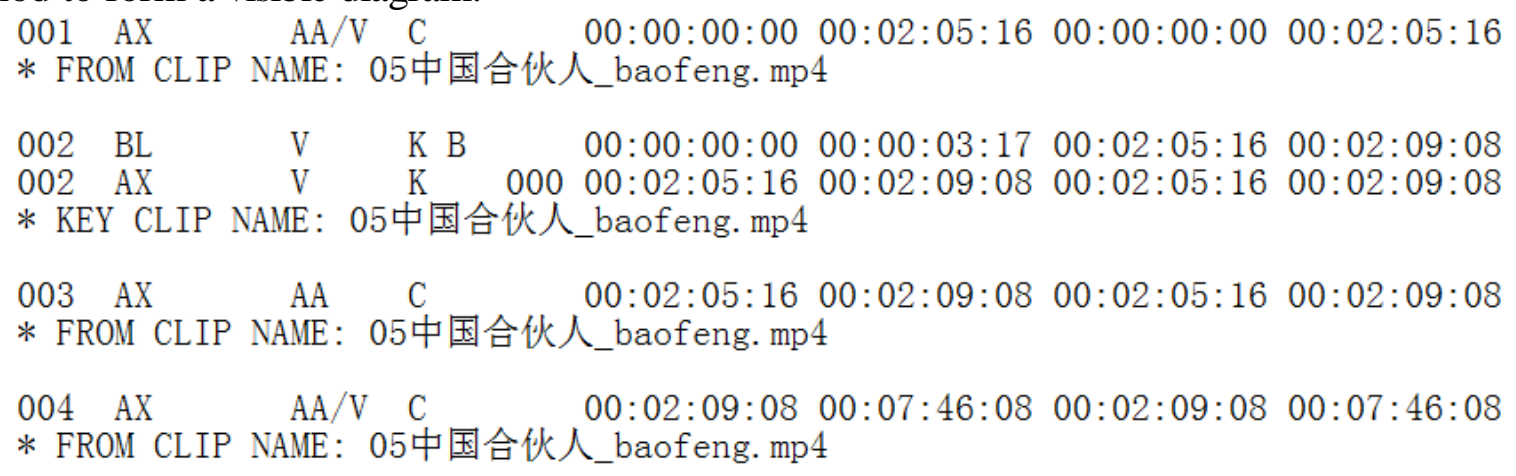

Fig. 1 the screenshots for EDL of American dreams in China

\section{The visual distribution of the trailers}

The distribution of the lenses of feature and trailer on the tracks is shown in figure 2. As a result of the non-linear editorial software's scaling, the lines above show the lenses of the trailer. The coarse ones means relatively more lenses were used in these positions and the thin ones mean the lenses were hardly used. From the trailer So Young we can see the lenses at the beginning and the end and lenses of certain plots were used more frequently.

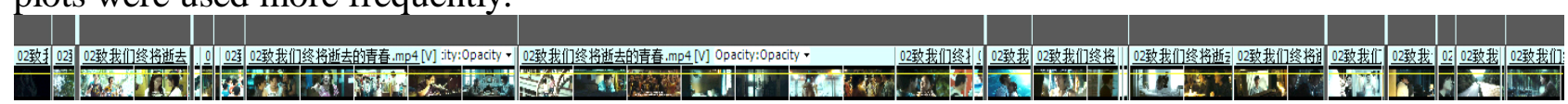

Fig. 2 The chart of trailer for So Young

In contrast, as shown in figure 3, the lenses in the trailer of American dreams in China are distributed widely in its feature. Besides, lenses at the beginning and the end of American dreams in China were also chosen to be used in the trailer. But different from So Young, the lenses here are not aggregated too much in some plots. 


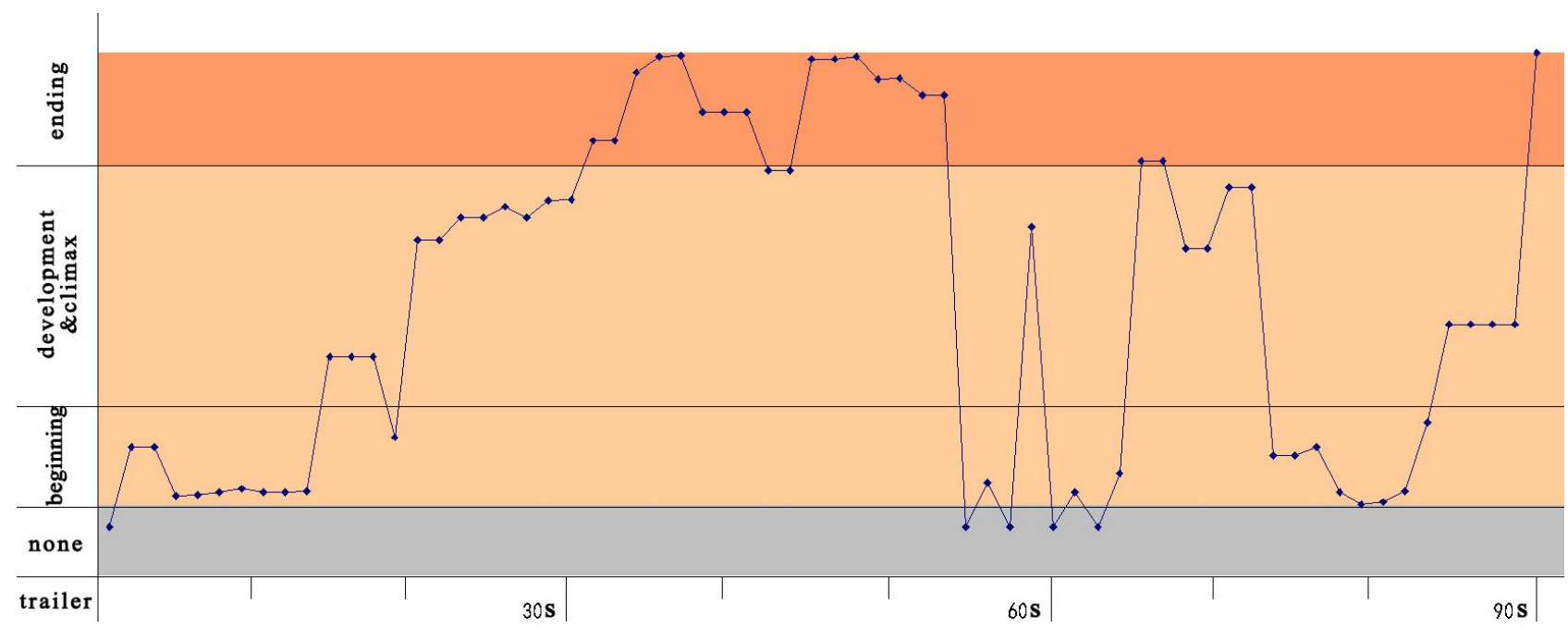

Fig. 4 The visualization of trailer for So Youth

\section{The data distribution of trailer lenses}

If we put the lenses used in the trailer back into its feature, we can get a diagram like figure 4, in which we can find out where the lenses belong to and finally see the true colors of the trailer.

In figure 4, the $\mathrm{X}$ axis stands for the distribution of the trailer lenses in time. And the $\mathrm{Y}$ axis stands for the exact positions of the trailer lenses in its feature. This diagram of showing the trailer lenses by time sequence can be regarded as a thumbnail of the whole movie. From figure 4, we can see that almost all of the lenses in the front body of So Young trailer were unfolded by the same sequence used in its feature in which we can obviously see some lenses of the ending part of the movie. But in the rest of trailer, there are few lenses from the feature. This is all because that after watching the trailer, the audience will discover that the trailer mainly aimed at prioritizing the relationships between the characters and telling the atmosphere and tune of the whole film. And that's why it doesn't need to follow the sequence of the feature and only need to select some key scenes at the beginning and introduce the actors with simple words. At last, it used some jumpy clips and switches the lenses of the beginning and end. Even in the end of the trailer, the ending lenses of the feature were still rarely cut into the trailer.

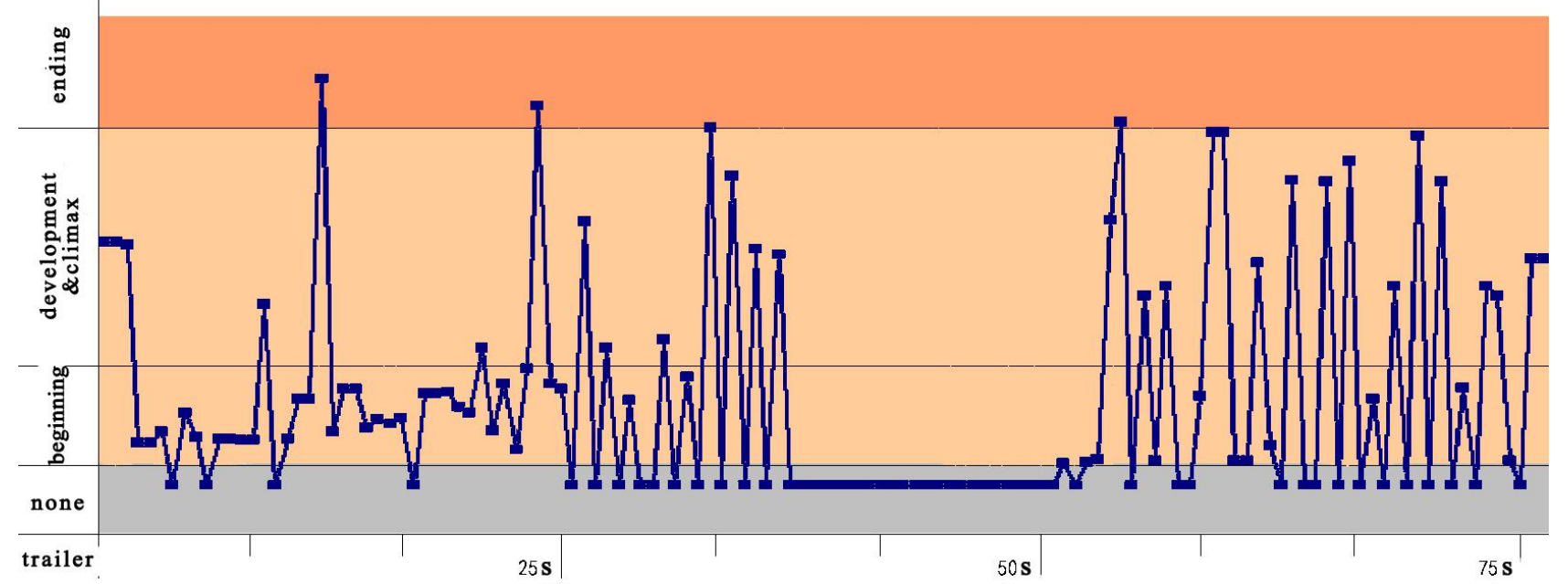

Fig. 5 The visualization of trailer for American dreams in China

Compared with So Young, trailer of American dreams in China is much shorter than that of So Young, but its lenses are twice as many as it. From the distribution diagram of trailer lenses in figure 5, 38 to 50 seconds of lenses were not shown in the trailer of American dreams in China. And the trailer is made up by lenses labeled with "love", "dream", and "fighting" which are related to the theme of the 
movie. Besides, there are also quick cutting between lenses. The switching method from 38 to 50 seconds is made up mainly by lenses with words, while from 50 second to the end, the transition method is black flash. Although the lenses at the end of the feature were used in the trailer, the trailer of the American dreams in China left more suspense to the audience than that of So Young. American dreams in China narrates the story from the end, and its trailer used some lenses from the beginning of the movie while in the meantime switched from the beginning and the highlight.

\section{Summary}

The standard of evaluating a film and a film trailer is definitely differently. Although both of them are narrative work, the aim of a trailer is too "tell a story in a right way" while the aim of the feature is to "tell a good story". As we all know that a good feature will not have a too bad trailer while a bad feature can always make a wonderful trailer. This just explained how hard it is to tell a integrated story. In a 120-minute movie, if some lens or scenes are not treated in the right way, it's easy to give the audiences bad impression. Although the trailers are short, they are the essence and highlight of a movie. It may not be able be tell the whole story, but it indeed carries a lot of information. If we compare the trailer and the movies as two individuals, the trailer is more likely to succeed than the movie. Thus, it's hard to know if a movie is good or bad simply by the trailer, but if we cut the best shot together, it will certainly be extremely impressive.

\section{Acknowledgement}

This research was financially supported by the Humanities and Social Sciences Researching Projects (Approval number: 14SKG14), Chongqing Education Commission and the Humanities and Social Sciences Planning Projects(Approval number: 2012YBJY073), Chongqing Education Commission.

\section{References}

[1] Xinxin Zhang, My University of Hollywood, Huacheng press, Guangzhou, 2003, pp.65.

[2] Feiwei Shao, The Trailer and its Implementation in the Film and Television Teaching, Journal of Art Education, vol.6, 2013, pp.120.

[3] Xiaoxiao Lin, Film Flower Trade - the Grammar of the Trailer and Strategy, Forum of Arts, vol.11, 2008.pp35.

[4] Xun Liu, The Influence of the Theory of Movie Trailers for the Film Industry, Movie Review, vol.2, 2013, pp120.

[5] Zhengfang Zheng, Movie Trailers Visual Expression Profiling, Southeast, vol.8, 2007, pp122.

[6] Information on http://www.tmtpost.com/37588.html

[7] Viktor Mayer-Schonberger, Big Data: A Revolution That Will Transform How We Live, Work and Think, John Murray Publishers Ltd, 2013.pp45. 